\title{
Utilization of Teleconsultation: Mitigation in Handling Mental Disorders in the COVID-19 Era
}

\author{
Haerawati Idris ${ }^{1}$ (D) \\ Published online: 9 June 2020 \\ (C) Springer Science+Business Media, LLC, part of Springer Nature 2020
}

\begin{abstract}
The COVID-19 pandemic has caused many undesirable effects, including death. The COVID-19 outbreak occurred suddenly, and many countries were ill prepared to face it. Community behaviour has been altered due to the pandemic. Uncertainty surrounding the disease triggered panic buying; public panic caused additional worry about limited food supplies, and thus demand increased. World economies have also felt the impacts of the COVID-19 outbreak. Owing to the measures put in place to address the spread of COVID-19, many service providers and industries were closed, resulting in financial losses, and the risk of unemployment was elevated, which inevitably increased negative emotions in individuals. A psychosocial consequence of the COVID-19 pandemic is worldwide fear. Because psychological defence is a supporting factor for the recovery of COVID-19 patients, it is important to encourage prevention of mental stress. Psychotherapy is able to provide counselling services to the community through teleconsultation. Strengthening psychological defences can help countries fight against this disease.
\end{abstract}

Keywords Mitigation · Teleconsultation · COVID-19 $\cdot$ Mental disorder

The COVID-19 outbreak occurred suddenly, and many countries were ill prepared to face it. Today, the world has been paralyzed by a virus $100 \mathrm{~nm}$ in size. Millions of cases have spread around the world, and billions of people are isolating themselves. Some countries are experiencing lockdowns, and global citizens are now enveloped in fear, worry, and anxiety (Ahorsu et al. 2020). Who knows when this condition will end? All the world over, people are waiting for drugs that can provide solutions to COVID-19.

Community behaviour has been altered due to the pandemic. This pandemic triggered panic buying; public panic caused worry about limited food supplies, and thus demand increased, which was a phenomenon that occurred worldwide. The media has been relating various

\section{Haerawati Idris}

haera@fkm.unsri.ac.id

1 Department of Health Policy \& Administration, Faculty of Public Health, Universitas Sriwijaya, Indralaya, Ogan Ilir, South Sumatera 30662, Indonesia 
reports about the spread and the danger posed by COVID-19 as well as the current unavailability of drugs to treat it. Unsurprisingly, a psychosocial consequence of the COVID-19 pandemic is worldwide fear (Pakpour and Griffiths 2020).

Broad media coverage of the current epidemic can affect the physical and psychological response of the community to the threat of infectious diseases, which may increase people's worries (Ho et al. 2020). Excessive anxiety can cause a decline in the immune system's ability to stave off infections. Those who are sick or quarantined may experience shame, guilt or stigma in the community. In addition, in the wake of this pandemic, several communities have developed a new mutual discrimination within as well as against Asian/Chinese societies (Lin 2020).

This pandemic is having an impact on people's mental health. A survey was conducted in China during the initial COVID-19 outbreak. The study found that $53.8 \%$ of respondents rated the psychological impact of this outbreak as moderate or severe, $16.5 \%$ reported experiencing moderate to severe depressive symptoms, $28.8 \%$ reported moderate to severe anxiety symptoms, and $8.1 \%$ reported moderate to severe stress levels (Wang et al. 2020). Other studies also report a high psychological prevalence of longer quarantine duration correlated with depressive symptoms (Hawryluck et al. 2004).

World economies have also felt the impacts of the COVID-19 outbreak. The widespread closures of service providers and industries have resulted in financial losses and increased the risk of unemployment, which certainly increases negative emotions for individuals (Van Bortel et al. 2016). Likewise, health care workers and health service providers can become depressed due to fatigue while on duty. A study reported that high-risk health care workers, such as medical staff and ambulance workers, who treated infected patients showed increased depression and anxiety (McAlonan et al. 2007). Some countries that experienced this outbreak early on (China and Singapore) took steps in the form of emergency psychological crisis interventions for people affected by COVID-19. Psychological defences are a supporting factor for the recovery of COVID-19 patients. It is therefore important to encourage prevention of these mental health disorders.

Nowadays, people really need an understanding of mental health to be psychologically prepared. The government can help accomplish this by providing access to psychotherapy, which is able to provide counselling services in the community through teleconsultation using several online-based facilities/video conferencing platforms, such as Zoom and WeChat, or via phone for free. Technically, the government can provide a call center (assistance hotline) to facilitate services. The virtual platform will be very useful for patients who are infected and treated in isolation rooms, including those who are isolated at home, health care workers, and the general public who need information. Psychotherapy can provide reassurance to patients and help health care workers interact with and support patients. Mental health service development lessons have been implemented in China, where online mental health services were available during the initial COVID-19 outbreak (Liu et al. 2020). Maintaining the confidentiality of participants data must be addressed.

Owing to public stress and panic related to uncertainty regarding COVID-19, education about mental health is essential to improve social conditions, especially with a focus on achieving a positive mindset, stress management, and relaxation techniques. The focus of the government is currently on preventing physical and biological transmission and the handling of COVID-19 cases; however, the handling of the social impact of the outbreak remains limited. The government needs to collaborate with all parties. Mental health teams are needed to provide mental health support to patients, health care workers, and the community. 
Strengthening psychological defences can help countries in the fight against COVID-19. Implementation of this idea can be done through the provision of voluntary psychotherapy, call center support (free of cost), and online-based facilities/video conferencing platforms, such as Zoom and WeChat.

Data Availability This article has no data openly available.

\section{Compliance with Ethical Standards}

Conflict of Interest The authors declare that they have no conflicts of interest.

Ethical Statement This article did not have any research ethical consideration as authors did not perform research with human or animal subjects.

\section{References}

Ahorsu, D. K., Lin, C.-Y., Imani, V., Saffari, M., Griffiths, M. D., \& Pakpour, A. H. (2020). The fear of COVID19 scale: development and initial validation. International Journal of Mental Health and Addiction, 1-9. https://doi.org/10.1007/s11469-020-00270-8.

Hawryluck, L., Gold, W. L., Robinson, S., Pogorski, S., Galea, S., \& Styra, R. (2004). SARS control and psychological effects of quarantine, Toronto, Canada. Emerging Infectious Diseases, 10(7), 1206.

Ho, C., Chee, C., \& Ho, R. (2020). Mental health strategies to combat the psychological impact of COVID-19 beyond paranoia and panic. Annals of the Academy of Medicine, Singapore, 49(1), 1-3.

Lin, C.-Y. (2020). Social reaction toward the 2019 novel coronavirus (COVID-19). Social Health and Behavior, $3(1), 1$.

Liu, S., Yang, L., Zhang, C., Xiang, Y.-T., Liu, Z., Hu, S., \& Zhang, B. (2020). Online mental health services in China during the COVID-19 outbreak. The Lancet Psychiatry, 7(4), e17-e18.

McAlonan, G. M., Lee, A. M., Cheung, V., Cheung, C., Tsang, K. W., Sham, P. C., et al. (2007). Immediate and sustained psychological impact of an emerging infectious disease outbreak on health care workers. The Canadian Journal of Psychiatry, 52(4), 241-247.

Pakpour, A., \& Griffiths, M. (2020). The fear of COVID-19 and its role in preventive behaviors. Journal of Concurrent Disorders. Available in http://irep.ntu.ac.uk/id/eprint/39561. Aceeseed 06 Apr 2020.

Van Bortel, T., Basnayake, A., Wurie, F., Jambai, M., Koroma, A. S., Muana, A. T., et al. (2016). Psychosocial effects of an Ebola outbreak at individual, community and international levels. Bulletin of the World Health Organization, 94(3), 210.

Wang, C., Pan, R., Wan, X., Tan, Y., Xu, L., Ho, C. S., \& Ho, R. C. (2020). Immediate psychological responses and associated factors during the initial stage of the 2019 coronavirus disease (COVID-19) epidemic among the general population in China. International Journal of Environmental Research and Public Health, 17(5), 1729 .

Publisher's Note Springer Nature remains neutral with regard to jurisdictional claims in published maps and institutional affiliations. 